\title{
Preparing Health Profession Students for Practice in Complex Real World Settings: How Do Educators Respond to a Model of Capability?
}

\author{
*Sally Hanks ${ }^{a}$, Hilary Neve ${ }^{a}, \&$ Thomas Gale ${ }^{a}$ \\ a: University of Plymouth, United Kingdom
}

\begin{abstract}
Undergraduate education often leaves future healthcare professionals insufficiently prepared for the complex and unpredictable workplace. Competency-based medical education (CBME) is widely utilised in health professions' education, but a growing literature highlights its limitations. Capability is a complex concept which builds on competence, while embedding the integration and adaptation of knowledge, skills and personal qualities. While capability can prepare learners for uncertainty and complexity, the concept has been slow to progress within health professions' education. We introduced the concept of capability to over 110 international health profession educators through six conference workshops, using a visual model to facilitate understanding. Participants' post-workshop qualitative feedback was collated and thematically analysed. One hundred and thirty-three free text comments were received and four main themes identified: conceptualising capability, capability as curriculum goal, educating for capability, challenges to implementation. The need for capability resonated with participants, although most were unfamiliar with the concept prior to the workshop. The workshop enabled participants to recognise the limitations of CBME's 'tick box' culture when preparing learners to address complexity. The model helped educators grasp the concept of capability and its potential value in health professions' education. Participants were then able to identify challenges and suggest approaches for implementing capability in practice. Educating for capability is fundamental for preparing students successfully for the 'real world' of professional practice. Most participants agreed it should be the end goal of healthcare education curricula. Healthcare educators are likely, however, to need support to embrace this paradigm shift.
\end{abstract}

Keywords: capability; competency-based education; complexity; prepared for practice

\begin{tabular}{l}
\hline *Corresponding Author: Dr. Sally Hanks, Peninsula Dental School, University of Plymouth John Bull Building, \\
16 Research Way, Plymouth, Devon, PL6 8BU United Kingdom
\end{tabular}

Journal URL: https://publications.coventry.ac.uk/index.php/pblh

Hanks, S., Neve, H., \& Gale, T. (2021). Preparing health profession students for practice in complex real world settings: how do educators respond to a model of capability? International Journal of Practice-based Learning in Health and Social Care, 9(1), 50-63 DOI 10.18552/ijpblhsc.v9i1.749.

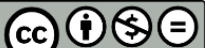

BY NC ND (C) 2021 Sally Hanks, Hilary Neve, \& Thomas Gale. This Open Access article is distributed under the terms of the Creative Commons Attribution Attribution-Non-Commercial No Derivatives 4.0 International License (https://creativecommons.org/licenses/by-nc-nd/4.0/ ), which permits unrestricted noncommercial use, distribution, and reproduction in any medium, provided the original work is properly cited and is unaltered. 


\section{Introduction}

What is the difference between achieving a qualification and performing in a job? As health profession graduates move into the world of work they face new challenges. They are now required to apply their skills and knowledge autonomously, safely and appropriately, often in unfamiliar environments. This is referred to as being 'prepared for practice' and there is evidence to suggest that newly qualified health professionals including doctors, dentists and nurses may not be fully equipped for the complex, uncertain and emotional situations in which they find themselves (Monrouxe et al., 2014; Whitehead \& Holmes, 2011; Hanks et al., 2018). Indeed, for many this is "the first time they assume full responsibility for a patient's care ... regardless of the complexity of the case" (Caverzagie et al., 2017, p. 59).

Qualification usually requires health professionals to meet a series of learning outcomes and competencies detailed by regulatory bodies. These tend to be listed as discrete, mutually exclusive entities. They are often taught and assessed in isolation from each other, implying that the achievement of a series of individual competencies is sufficient to prepare trainees for professional performance (Hawkins et al., 2015; Glass, 2014; ten Cate \& Scheele, 2007).

In this article, we summarise the critiques of, and challenges to, competency-based education (Caverzagie et al., 2017; Hawkins et al., 2015; ten Cate \& Scheele, 2007), and discuss the pedagogic concept of capability and how it can potentially address these critiques. Capability has been little explored within health professions' education and, in our experience, the concept can be hard for educators to grasp. We introduce a visual model designed to facilitate an understanding of capability and share educators' responses to this.

\section{Competence in heath profession education}

Competence is defined as what individuals know or are able to do in terms of knowledge, skills and behaviours (Hawkins et al., 2015). To be seen as reproducible, defensible and 'fair' to all, teaching, learning and assessment of competencies are often standardised and carried out in stable, predictable settings, using familiar problems (Wass et al, 2001; Gardner et al., 2008). It tends to be assumed that competencies performed in these environments are generalisable to the workplace, but there is little evidence to support this (Glass, 2014; Rethans et al., 2002).

Critiques of competency-based education challenge its dependence on standardised testing of easily measurable knowledge and skills as being artificially reductionist (Gardner et al., 2008; Rethans et al., 2002; Fraser \& Greenhalgh, 2001). They argue that this excludes the harder to measure, more complex abilities that a practitioner requires to function successfully, including those related to humanism and professionalism (Hawkins et al., 2015). These are rarely mentioned in the competency literature, meaning that assessment criteria may not adequately reflect patient and community needs (Caverzagie et al., 2017). Teaching and assessing competencies in isolation can, it is argued, encourage mimicry rather than deep understanding; promote linear rather than networked learning; and reduce the authenticity of learning by 'dislocating' content knowledge from important contextual and experiential knowledge (Wheelahan, 2007). Clinical performance is not a "simple linear addition of the various dimensions being assessed" (Ginsburg et al., 2010, p. 785) but a complex set of reciprocal interactions, where "the whole tends to exceed the sum of its parts" (Durning et al., 2015, p.233). The important role of teamwork in healthcare is also frequently missing from competency-based learning approaches (Kalet et al., 2017).

In the UK, the General Medical Council (2015, p. 4) has acknowledged that "knowing when not to take action.... when guidelines and protocols do not cover the situation" is equally important as "ticking the competency box". Iedema (2011) uses the term 'articulation work' to describe how clinicians resolve tensions between conflicting elements of a complex work situation (e.g. practical constraints versus professional best practice standards) and argues that "standardisation cannot cater for all possible circumstances and risks" (Iedema, 2011,p. 183). Bates et al. (2019) point out that standardisation and contextual diversity are often seen as separate, competing philosophies, and suggests that education should instead attend to the interplay between them. This links to the notion of 'adaptive expertise', where clinicians balance efficiency and innovation within the ever-changing workplace (Pusic et al., 2018). 


\section{Capability: recognising the concept}

The notion of capability within higher education was explored by Stephenson in 1998 and subsequently within health professions' education (Gardner et al., 2008; Neve \& Hanks, 2016; O'Connell et al., 2014; Rees \& Richards, 2004). Capability has been described as an integration of knowledge, skills, personal qualities and understanding, used appropriately and effectively; not just in familiar and specialist contexts, but in response to new and changing circumstances. In 2001, Fraser and Greenhalgh argued that in the complex world of healthcare, "we must educate not merely for competence, but for capability" (p. 799). Twelve years later Baillie et al. (2013) were still calling for "capability to act...as the central curriculum goal in undergraduate education for the professions" (p. 229). Despite such calls for change, the idea has been slow to progress within health professions' education, although nursing has been more responsive to the concept (O'Connell et al., 2014).

Perhaps this is not surprising. Understanding capability can involve a major conceptual shift for educators, and embedding such complexity can be immensely challenging within a system that champions standardisation and 'black and white' thinking in order to defend outcomes to students and refute appeals. This was also our experience. We found that many of our colleagues, including those who understood the complex nature of healthcare and felt that there was 'something missing' in current education practice, found the concept of capability initially troublesome to grasp, and even harder to operationalise. The concept of capability may be troublesome to understand for a number of reasons (Perkins, 2006) - it is complex, may initially seem abstract and may conflict with educators' existing views and educational practices. The use of simple and familiar analogies can facilitate understanding of difficult or complex concepts and make abstract concepts more concrete and memorable (Bishop, 2006). Having previously used the analogy of the television programme, MasterChef ${ }^{\odot}$, to explain capability (Neve \& Hanks, 2016), we decided to develop a conceptual model (Jabareen, 2009), based on the literature, which uses analogy to communicate the integrative, adaptive and complex features of capability.

We introduced the model at a series of interactive conference workshops for health profession educators. In doing so, we aimed to:

- gain insights into health profession educators' responses to our use of a visual model to explore the concept of capability

- identify perceived barriers to implementing capability in education practice and potential approaches for overcoming these

\section{Methods}

\section{The capability model}

The model is based on the capability literature described earlier and uses visual cues and analogy to facilitate understanding of the capability concept. It is designed so that its elements can be introduced in stages (see Figure 1, Figure 2a, Figure 2b, and Figure 3).

Miller's pyramid (Miller, 1990) is a widely used framework used in assessment which ranks competence from knowledge (at the lower levels) to action (at the higher). Our first stage (Figure 1) involved inverting a Miller-type pyramid to demonstrate how capabilities are broader than competencies and become broader as expertise develops. The pyramid also illustrates how capability is grounded in complex clinical practice, rather than being 'up in the clouds', divorced from reality. 
Figure 1: Upending Miller's pyramid

\section{Capability}
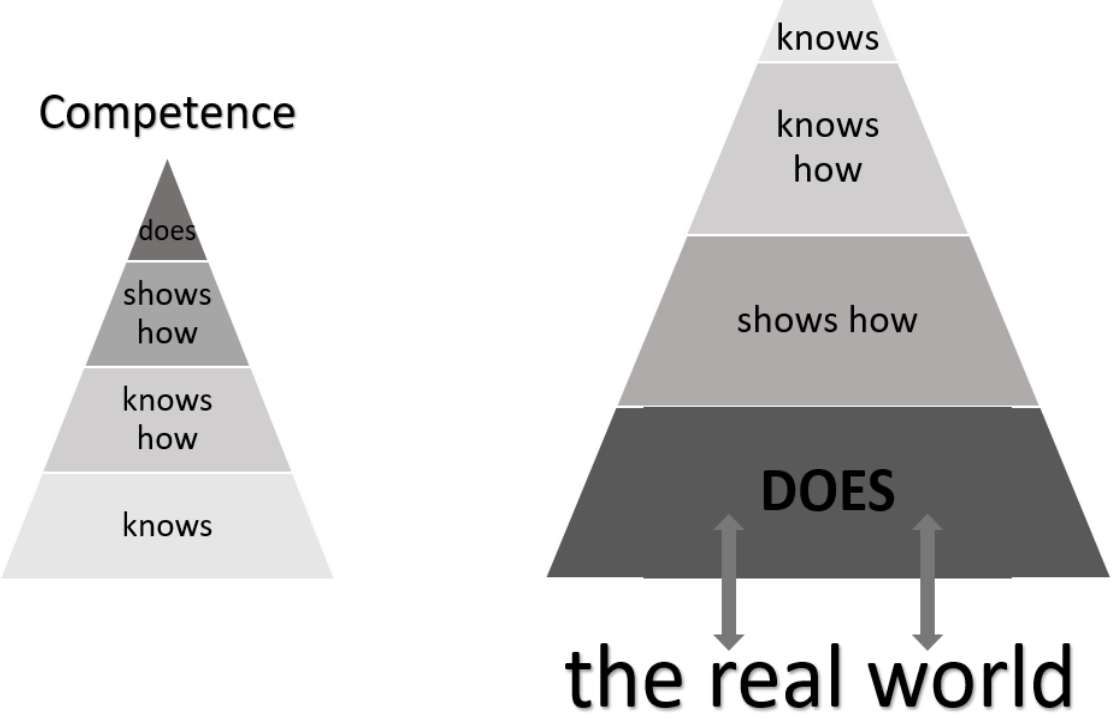

Figure 2a uses an iceberg analogy to reflect how capability is underpinned by the effective integration of multiple competencies, depicted by the overlapping competence pyramids hidden below the water's surface.

Figure 2a: Integrating competencies

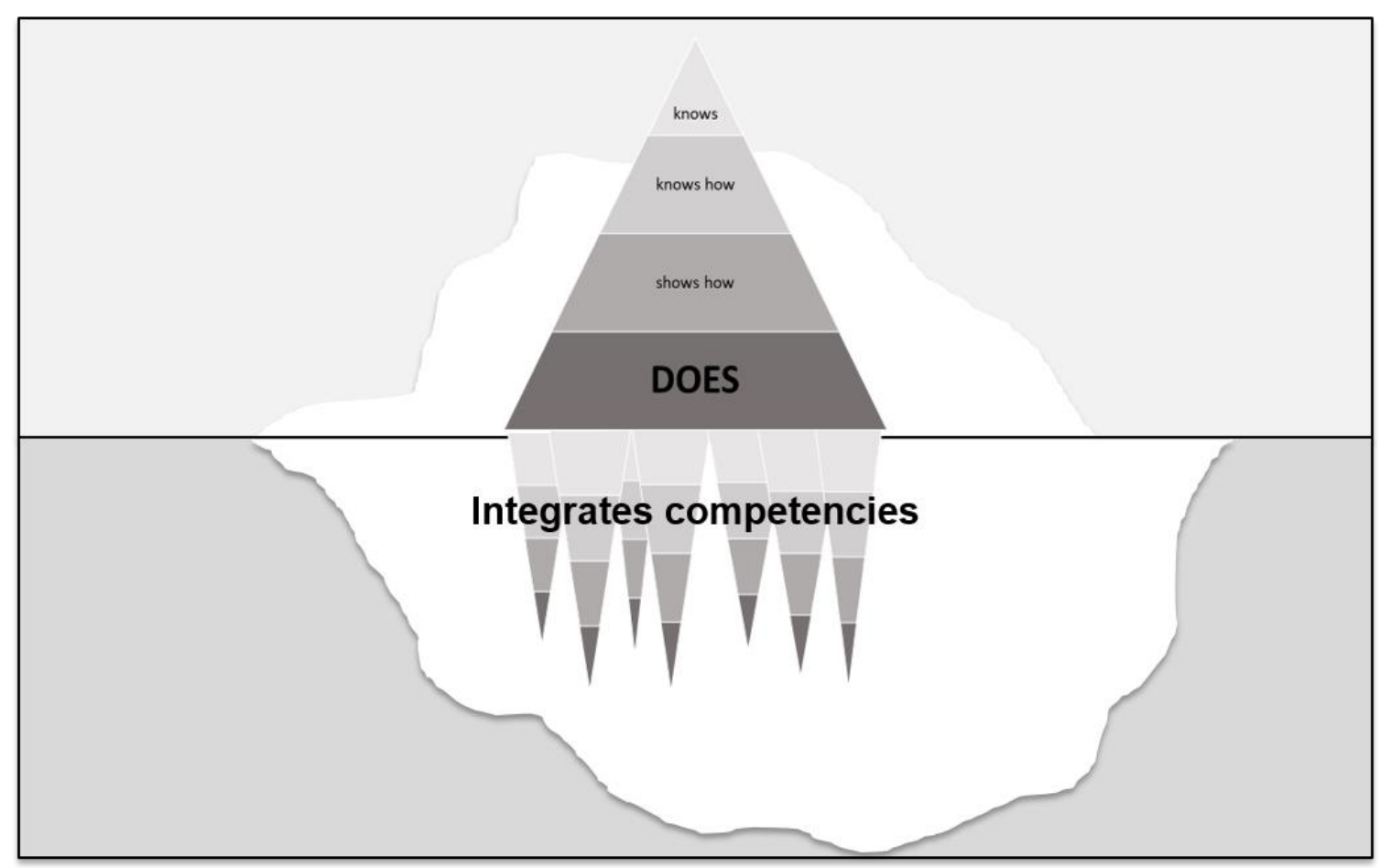


Figure $2 \mathrm{~b}$ demonstrates how working effectively in complex settings requires health professionals to further apply and integrate a range of personal skills and attributes. Inevitably at this stage, the model starts to reflect the complexity of the capability concept.

Figure 2b: Integrating skills and attributes

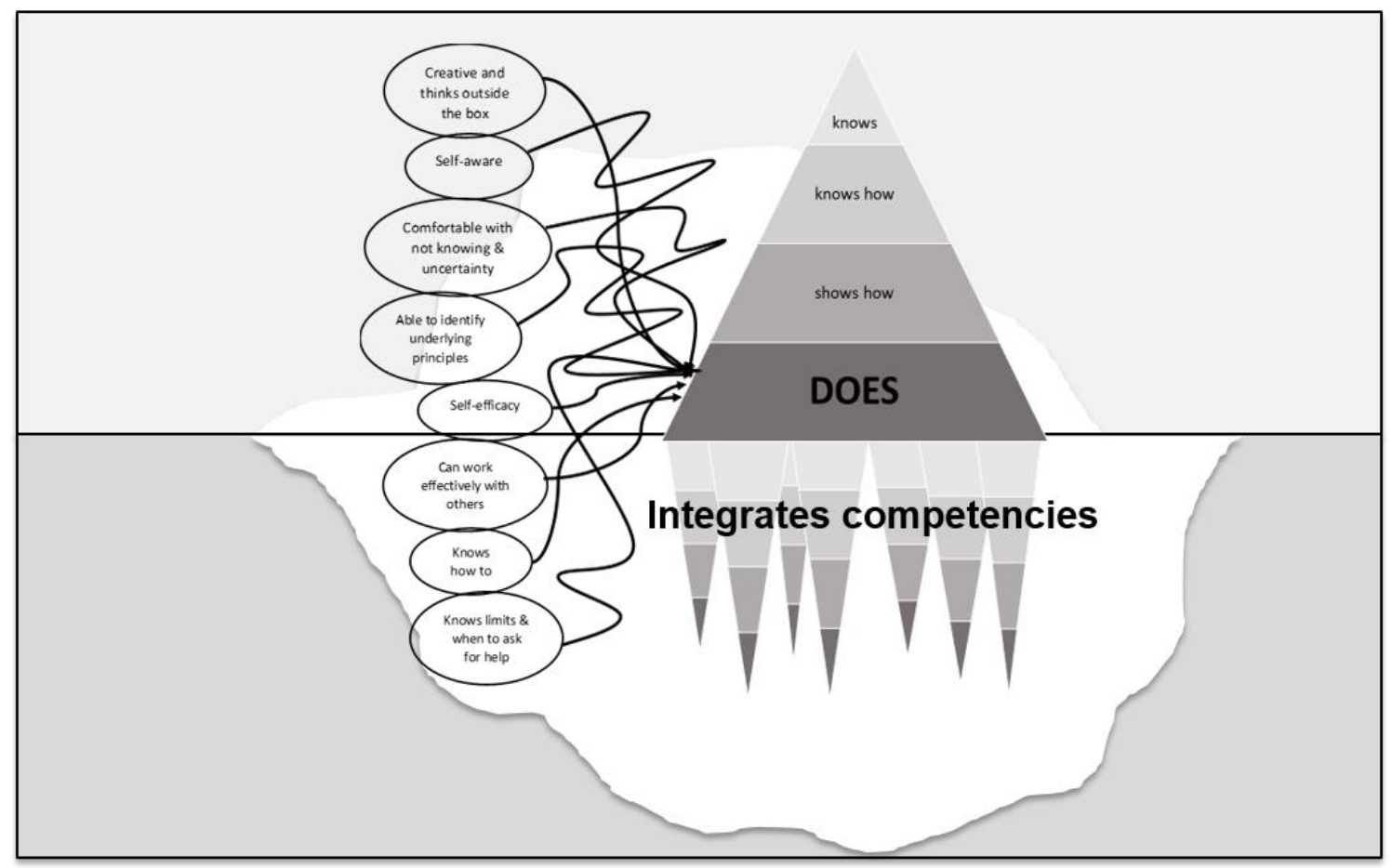

Figure 3 uses the analogy of global warming and climate change to acknowledge the uncertainty and ever-changing environment in which healthcare occurs. The sun and calving iceberg emphasise how capability requires health professionals to be flexible, willing and able to adapt to unpredictable and changing situations.

\section{Capability workshops}

The capability model was used to introduce and explore the concept of capability through six participatory workshops held at national and international conferences for health profession educators. We summarised some of the challenges to competency-based education and introduced our capability model in stages (Figure 1, Figure 2a, Figure 2b and Figure 3) to discuss how capability might help address some of these challenges. To support understanding further, we also shared an expanded, interactive, version of the 'MasterChef ${ }^{\mathcal{O}}$ ' analogy, we had published previously (Neve \& Hanks, 2016). We showed video clips illustrating (i) how novice students in clinical settings often apply competencies in a linear, rather than integrated, way; and (ii) how debriefing following a simulation activity can support students to identify and reflect on their thinking processes during the activity. At the end of each workshop delegates were asked to respond to two questions on sticky notes:

The questions were:

(1) What, if anything, has got you thinking differently today?

(2) How will you implement or enhance capability in your curricula or teaching?

\section{Data analysis}

Sticky note comments were transcribed verbatim into a spreadsheet and the data analysed thematically (Saldaña, 2013). Two authors (SH, HN) identified initial themes which were reviewed, negotiated and 
refined by all three authors and the data coded according to these themes. Themes were subject to iterative cycles of analysis until all data had been included, and theoretical saturation was reached.

Ethical approval was reviewed by the Chair of our Faculty of Health Ethics Committee, who considered full approval by the committee was not required.

Figure 3: The capability model

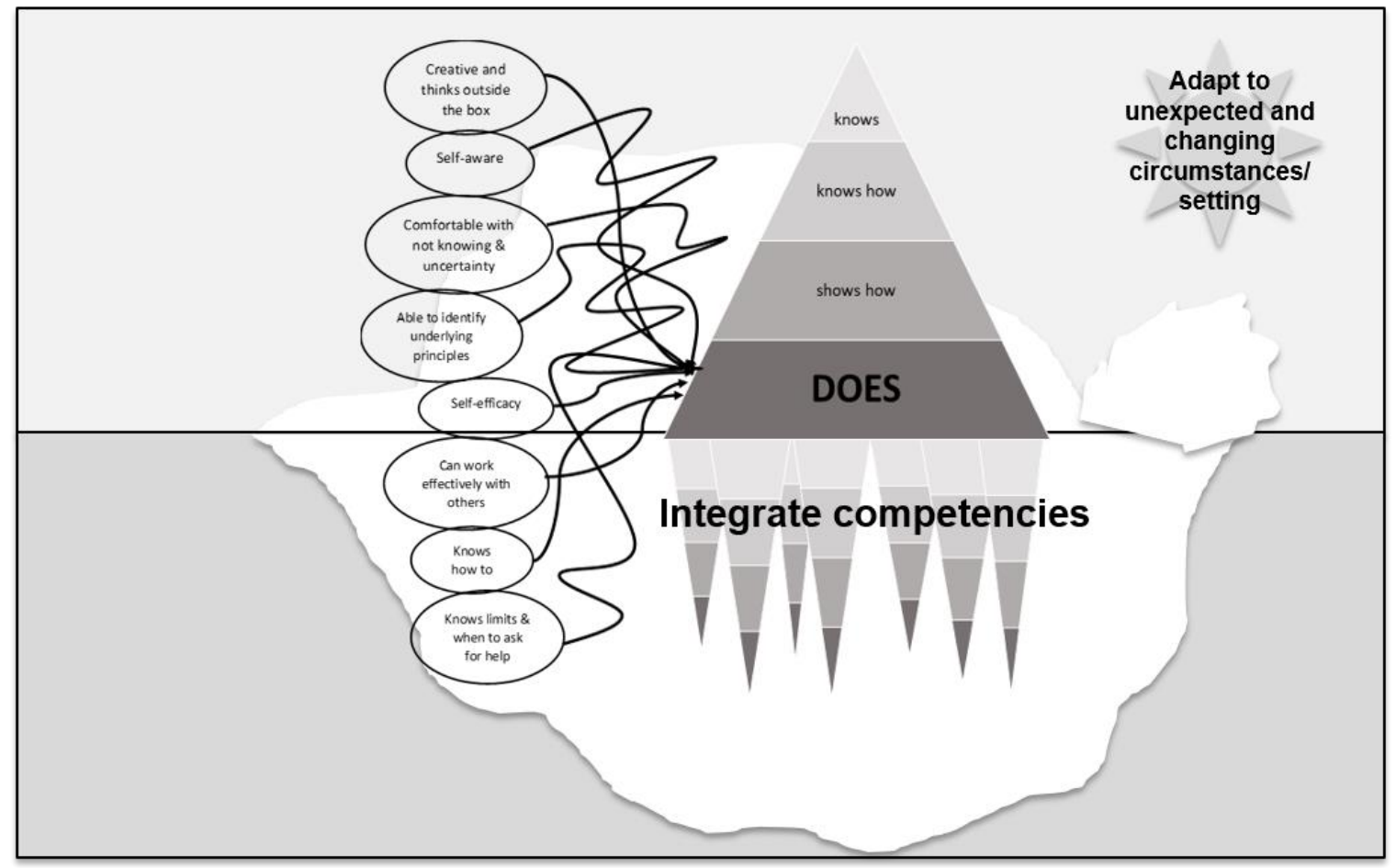

\section{Findings}

Over 110 healthcare educators from a range of professions, including nursing, medicine and dentistry, took part in six workshops from 2017 to 2019. Workshop size ranged from 12 to 30 delegates. Completing the sticky notes was voluntary, and 133 responses were received (64 responses to the first question and 69 to the second). Responses were anonymised and no demographic data was collected from individuals. The final cycle of coding resulted in overarching themes (Table 1) and sub themes (Table 2, $\underline{\text { Table } 3}$ and Table 4).

Table 1: Overarching themes relating to capability from workshop participants

\begin{tabular}{|l|l|}
\hline Theme $\mathbf{1}$ & Conceptualising capability \\
\hline Theme $\mathbf{2}$ & Capability as a curriculum goal \\
\hline Theme 3 & Educating for capability \\
\hline Theme 4 & Challenges to implementation \\
\hline
\end{tabular}


Table 2: Themes 1 and 2 - Conceptualising capability and Capability as a curriculum goal

\begin{tabular}{|c|c|c|}
\hline Theme & Sub theme & Illustrative quotation(s) \\
\hline \multirow{4}{*}{$\begin{array}{l}\text { Conceptualising } \\
\text { capability }\end{array}$} & $\begin{array}{l}\text { Recognising the } \\
\text { concept }\end{array}$ & $\begin{array}{l}\text { 'Is capability what competence was MEANT to be?' } \\
\text { 'I think we probably are [using capability]- but perhaps } \\
\text { we don't use that word!'’ } \\
\text { 'It's a bit like situation awareness, but developed' }\end{array}$ \\
\hline & $\begin{array}{l}\text { Integration, } \\
\text { adaptation \& } \\
\text { complexity }\end{array}$ & $\begin{array}{l}\text { 'Amazing workshop - capability is a way of integrating } \\
\text { competences' } \\
\text { 'Professional skills cannot be 'discrete' - they are } \\
\text { integrated' } \\
\text { 'Capability is what we need to achieve in learners and that } \\
\text { it is about integration and flexibility' } \\
\text { 'I like...its focus on adaptation' }\end{array}$ \\
\hline & $\begin{array}{l}\text { Relationship with } \\
\text { competence }\end{array}$ & $\begin{array}{l}\text { 'Separating out competence and capability was really } \\
\text { useful - understanding the complexities now' } \\
\text { 'Competence of skills in simulation not the same as } \\
\text { [capability] on the wards' } \\
\text { 'Competence is inside capability' } \\
\text { 'I see it as a continuum: from simple to complex / from } \\
\text { checklist to capability' }\end{array}$ \\
\hline & Use of analogy & $\begin{array}{l}\text { 'Your metaphors are so helpful for seeing things from } \\
\text { different perspectives and for making it memorable and } \\
\text { simplifying the complexity so it is more accessible' } \\
\text { 'I love the MasterChef metaphor which has explained it } \\
\text { really well' }\end{array}$ \\
\hline \multirow[b]{2}{*}{$\begin{array}{l}\text { Capability as } \\
\text { curriculum goal }\end{array}$} & $\begin{array}{l}\text { Limitation of } \\
\text { competence }\end{array}$ & $\begin{array}{l}\text { 'It takes more than being competent to be prepared for } \\
\text { practice' } \\
\text { 'Life is not a tick box!' } \\
\text { 'That our students may have false sense of security that } \\
\text { we might be responsible for!' }\end{array}$ \\
\hline & $\begin{array}{l}\text { Preparing for real } \\
\text { world }\end{array}$ & $\begin{array}{l}\text { 'We should be re-thinking what our students need to be } \\
\text { aiming for and our expectation/goals for them' } \\
\text { 'Capability is about practice in the real world - not sure } \\
\text { we are allowing students/FYs to do this' } \\
\text { 'Make them think about what they are trying to achieve } \\
\text { and use capability to solve this' }\end{array}$ \\
\hline
\end{tabular}


Table 3: Theme 3 - Educating for capability

\begin{tabular}{|c|c|c|}
\hline Theme & Sub theme & Illustrative quotation(s) \\
\hline \multirow{5}{*}{$\begin{array}{l}\text { Educating for } \\
\text { capability }\end{array}$} & Curriculum design & $\begin{array}{l}\text { 'More opportunities for non-standardised simulation?' } \\
\text { 'Challenge our students in 'surprise situations' more } \\
\text { frequently' } \\
\text { 'Introduce 'I don't know' as the correct answer } \\
\text { sometimes?' }\end{array}$ \\
\hline & $\begin{array}{l}\text { Real world } \\
\text { environment for } \\
\text { teaching \& } \\
\text { assessment }\end{array}$ & $\begin{array}{l}\text { 'Focus on real practice context - how to integrate skills } \\
\text { and increase debrief sessions' } \\
\text { 'Teaching, assessing and giving feedback on clinical skills } \\
\text { in real clinical areas in real time'. }\end{array}$ \\
\hline & $\begin{array}{l}\text { Authentic } \\
\text { assessment }\end{array}$ & $\begin{array}{l}\text { 'Assess capability by more qualitative assessments; more } \\
\text { real-life assessments' } \\
\text { 'Rethink work-based assessments to look at capability' } \\
\text { 'Advocate oral assessment as a means of increasing } \\
\text { insight into students thinking process' }\end{array}$ \\
\hline & $\begin{array}{l}\text { Move away from } \\
\text { tick box }\end{array}$ & $\begin{array}{l}\text { 'I will not be so concerned about standardising } \\
\text { assessments and work more on understanding how the } \\
\text { students decided to do something not what they did' } \\
\text { 'Develop/advocate broader conception for 'assessment' } \\
\text { (evaluation, reflection...) focused on capability rather than } \\
\text { competency' }\end{array}$ \\
\hline & $\begin{array}{l}\text { Opportunity for } \\
\text { reflection including } \\
\text { debrief }\end{array}$ & $\begin{array}{l}\text { 'I am going to use [the model] as prompts for debrief } \\
\text { sessions....... as I feel we need to start somewhere } \\
\text { immediately' } \\
\text { 'I will absolutely use your model when debriefing } \\
\text { simulations' } \\
\text { 'Instead of just giving feedback on performance, asking } \\
\text { about trainees' thought processes while they were } \\
\text { performing a task or assessing a patient' } \\
\text { 'Use of debrief to tease out integration of skills/knowledge } \\
\text { and adaptability/invention' }\end{array}$ \\
\hline
\end{tabular}


Table 4: Theme 4: Challenges to Implementation

\begin{tabular}{|c|c|c|}
\hline Theme & Sub theme & Illustrative quotation(s) \\
\hline \multirow{4}{*}{$\begin{array}{l}\text { Challenges to } \\
\text { implementation }\end{array}$} & $\begin{array}{l}\text { Safer, more } \\
\text { straightforward to } \\
\text { assess competence }\end{array}$ & $\begin{array}{l}\text { 'We are very comfortable with competence because it } \\
\text { feels 'safe' to assess it' } \\
\text { 'Knowing that I should be educating for capability but } \\
\text { only assessing for competency because it is easier' } \\
\text { 'How to make our assessments more 'masterchef' but still } \\
\text { reliable and valid and fair for all' }\end{array}$ \\
\hline & $\begin{array}{l}\text { Organisational } \\
\text { constraints }\end{array}$ & $\begin{array}{l}\text { 'How to implement capability within the constraints of } \\
\text { current assessment' } \\
\text { 'It makes perfect sense but I have no idea how to include } \\
\text { it as I would be fighting against the number crunching } \\
\text { and standardising of assessments to make it 'fair' to all' }\end{array}$ \\
\hline & $\begin{array}{l}\text { Difficult to } \\
\text { observe/measure }\end{array}$ & $\begin{array}{l}\text { 'Capability may not be observable and that may need } \\
\text { additional layer of assessment above 'observe'" } \\
\text { 'How do we assess situational awareness!' } \\
\text { 'Assessing capability is hard and difficult but so } \\
\text { important' }\end{array}$ \\
\hline & $\begin{array}{l}\text { Addressing the } \\
\text { challenges }\end{array}$ & $\begin{array}{l}\text { 'I will be more purposeful in pointing out to faculty and } \\
\text { students the benefits to developing capability' } \\
\text { 'Start a debate about competencies vs capability' } \\
\text { 'Would like the students to come to this workshop!' } \\
\text { 'Run workshops - reflective practice vs competence vs } \\
\text { capability' } \\
\text { 'Knowing that we all have the same challenges } \\
\text { essentially' }\end{array}$ \\
\hline
\end{tabular}

\section{Discussion}

\section{Capability: Understanding the concept}

In this study, the idea that 'something more' is needed in order to prepare students for the real world of practice clearly resonated with participants' experiences. Although many were already grappling with this gap, the concept of capability, which was unfamiliar to most, was often deemed 'eye opening'. This was the case whether or not participants were already aware of the critiques of competency-based education. In line with the literature on troublesome knowledge (Perkins, 2006), introducing the capability model in stages during the workshop, together with the use of analogy and video clips facilitated participants' grasp of the concept. Delegates identified the approaches used in the workshop, not only for aiding their own understanding, but also for facilitating the engagement of others in future; including faculty, colleagues and students. Participants often mentioned the model (or 'framework'), or its components, such as its use of analogy and the inverted Miller's pyramid, as particularly useful and commented on how they would use this to communicate capability to others.

Understanding the relationship and differences between competence and capability was a key factor in conceptualising capability; as was the recognition that clinicians need to be able to appropriately integrate and adapt skills, qualities and competencies according to the healthcare needs and context in which they are working. During the workshops we discussed how the concept of capability has been promoted in higher education since 1998 and how it aligns with other pedagogic ideas including adaptive expertise, 
contextual competence (Teunissen et al., 2021), performance and progression (Rethans et al., 2002; Pusic et al., 2018). The way that capability incorporates emotion and harder to measure, higher order cognitive processes including creativity, problem-solving and thinking outside the box appeared to resonate particularly with participants; many identified its relevance to 'preparedness for practice' and the real world as the thing that got them 'thinking differently', as well as influencing their ideas for implementation.

\section{Capability in health professions' education}

Demonstrating the relationship between capability, and existing well-established and embedded educational approaches, may aid initial understanding. As participants started to see these links, their ideas for how to implement capability in practice, and how to overcome potential barriers, were more forthcoming.

When considering assessment, delegates identified various challenges including the difficulty of observing and measuring capability, current system constraints, and concerns about reduced reliability. They recognised that the development of capability could be enhanced by moving away from using oversimplified tick boxes of competence-based assessment to more authentic assessments. Approaches they felt might be helpful included workplace-based assessments; simulation-based assessments; and carefully embedded Entrustable Professional Activities (EPAs) (ten Cate et al., 2018). This aligns with numerous calls in the literature for health professions' education to utilise, more authentic forms of assessment in order to differentiate between competence and performance (Glass, 2014; Rethans et al., 2002; Govaerts \& Van der Vleuten, 2013), and to promote ongoing learning (Eva et al., 2016).

While summative assessment was a particular focus of the workshops, discussions organically expanded into teaching and learning approaches as well as formative assessment. Reflection and debrief were seen as key methods to scaffold the concept of capability within the curriculum as well as for identifying the development of capability in students (Mann et al., 2009; Mounrouxe \& Rees, 2017; Swaffield, 2011). Participants also proposed mapping their curricula outcomes to the capability model, rather than to competences.

\section{Enhancing capability}

Participants welcomed the use of the capability label as a means of addressing educational issues about which they already had concerns. However, a potential source of confusion relates to the term 'capability'. In lay usage it can be synonymous with 'ability' or 'competence'. It has also been used in education to describe an approach whereby students make value choices around achieving their potential (Sandars \& Sarojini-Hart, 2015). In addition, in the United Kingdom, the General Medical Council (GMC) have used the term capability to define broad learning outcomes for graduates (General Medical Council, 2017), without explicitly highlighting the adaptive and integrative elements. We recognise that one of the major risks is that individuals may use the various elements included in the model as discrete entities to inform an oversimplified set of 'tick boxes'. Such inauthentic deconstruction would be the antithesis of capability and understanding this risk is important for educators. It is also important that the model is not viewed as all-encompassing or exhaustive, and that users can add elements of capability that they see as important within their particular contexts. These points were discussed explicitly in the workshops.

The difficulties both in understanding and operationalising the concept of capability may go some way to explaining the time lag between the early literature and wider acceptance and application in education practice. As the concept and model become more widely available, we hope more educators will engage with the concept and develop ideas for incorporating capability into curricula. Further work is needed to identify and research effective approaches for this. Delegates suggested various ways, many of which are supported by education literature and which we intend to include in future training. Reflection through writing, in small groups and using post-encounter probes (Eva et al., 2016), can help learners become more comfortable with complexity and uncertainty by questioning their responses to complex and difficult situations; engaging with emotions such as fear and anxiety as they experienced them; and articulating their thinking processes to explore why they took particular actions or ruled out others. In 
addition, problem-based or enquiry-based learning can help students develop knowledge capability by identifying the underlying principles in unpredictable, complex situations and successfully apply their knowledge to deal with these (Neve et al., 2018; Castillo et al., 2018). Activities such as 'compare and contrast' and requiring students to apply knowledge and skills to 'near' and 'far' scenarios, can also assist them to adapt prior learning (Hay et al., 2008). The model itself could also be used to explore the dilemmas that learners experience in healthcare settings, and to discuss the skills and attributes that could help address such 'no single right answer' scenarios. Explicitly demonstrating to learners how they are integrating multiple competences could facilitate their ability to problem solve in future complex situations and take more control of their own learning (Rethans et al., 2002).

Additional approaches for assessing capability, not specifically mentioned by participants, could be incorporated into future training. These include concept mapping to assess how learners understand and respond to non-linear scenarios and script concordance testing to explore how students respond to uncertainty in scenarios when additional data is added (Hay et al., 2008; Schuwirth \& Van der Vleuten, 2011). Qualitative narratives can provide rich data about learners' performance, for example in workbased settings, which may not be captured through numeric scores (Durning et al., 2015). There will always be a need to demonstrate both reliability and validity in assessment and collating data from multiple methods within an overall strategy can support this (Eva et al., 2016). The use of programmatic assessment strategies is a well-accepted curriculum approach where 'assessment of learning' is replaced by the concept of 'assessment for learning' (Schuwirth \& Van der Vleuten, 2011; Eva et al., 2016) and where educators provide judgements and feedback regarding the ability of students to integrate multiple skills and attributes in clinical practice. This could align well with capability. Indeed, a recent scientific review of the literature on competency-based medical education emphasised the need to balance the use of standardised assessments with opportunities for learners to embrace contextual diversity and develop capability (Bates et al., 2019).

\section{Strengths \& limitations of this study}

A strength of this study is that the workshops enabled the crossing of international boundaries and engaged new and experienced educators from different health professions. A limitation was that workshop delegates were self-selected and may have been already disposed to embrace the meta-level conceptual thinking required to engage with the complexity of capability. In addition, participants were asked to respond to just two specific questions and some, who may have given negative feedback, did not respond.

\section{Conclusions}

Our study suggests that health profession educators are ready for a paradigm shift in their education practice, which supports the concept of 'educating for capability'. The model and associated workshop appear to facilitate educators' understanding of capability, and participant feedback reinforced its importance in preparing students for the 'messy reality' of healthcare practice (Bleakley \& Cleland,

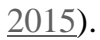

Workshop feedback confirmed that promoting, observing and assessing capability in practice is a challenge for educators. Promoting reflection and de-briefing, mapping curricula outcomes to capability, utilising programmatic approaches to assessment, and embracing contextual diversity could all facilitate the development of graduates who are able to respond effectively in the complex and unpredictable global healthcare environment.

Further innovation and empirical evaluation of strategies incorporating the concept into educational and assessment practice would contribute to what could become an ultimate goal of healthcare curricula. Work in different settings could explore how best to operationalise capability and how to refine or adapt the model for use in different settings. We ourselves plan to explore whether capability may be a threshold concept (Meyer \& Land, 2005). This was discussed in the workshops and would fit with the troublesome and fundamentally integrative nature of capability as well as its ability to transform. If so, our model may be one approach for supporting people through the liminal space and across the capability 
threshold. Threshold concepts are usually irreversible (Meyer \& Land, 2005) and this may explain why, in our experience, the concept of capability may be less of an 'aha' moment for some very experienced educators, who may not be aware of the concept, but are already comfortable with its underpinning ideas. Supporting wider faculty, in education and healthcare settings, to cross the capability threshold and address the concept of capability in practice is vital if we are to better prepare our future clinicians to not only gain a qualification, but also to do their job well.

\section{Acknowledgements}

The authors wish to thank all the delegates who attended conference workshops and advanced the development of the concept and model; Professor Ruth Endacott for co-delivering the workshop in Prato, Italy, and Dr Harry Carter for the workshop in Braga, Portugal.

\section{Sources of funding}

No funding was received, other than from the University of Plymouth to support conference attendance.

\section{ORCID}

Sally Hanks $\quad$ https://orcid.org/0000-0002-4072-4594

Hilary Neve $\quad$ https://orcid.org/0000-0003-1831-9821

Thomas Gale https://orcid.org/0000-0003-4551-5860

\section{References}

Baillie, C., Bowden, J. A., \& Meyer, J. H. F. (2013). Threshold capabilities: Threshold concepts and knowledge capability linked through variation theory. Higher Education, 65, 227-246. https://doi.org/10.1007/s10734-012-9540-5

Bates, J., Schrewe, B., Ellaway, R. H., Teunissen, P. W., \& Watling, C. (2019). Embracing standardisation and contextualisation in medical education. Medical Education, 53(1), 15-24. https://doi.org/10.1111/medu.13740

Bishop, S. (2006). Using analogy in science teaching as a bridge to students' understanding of complex issues. In J. H.F. Meyer, \& R. Land (Eds.), Overcoming barriers to student understanding: Threshold concepts and troublesome knowledge. (pp. 182-194.). Routledge.

Bleakley, A., \& Cleland, J. (2015). Sticking with messy realities: How 'thinking with complexity' can inform healthcare education research. In J. Cleland, \& S. J. Durning (Eds.), Researching medical education (pp. 81-92). Wiley Online Books. https://doi.org/10.1002/9781118838983.ch8

Castillo, J-M., Park, Y. S., Harris, I., Cheung, J. J. H., Sood, L., Clark, M. D., Kulasegaram, K., Brydges, R., Norman, G., \& Woods, N. (2018). A critical narrative review of transfer of basic science knowledge in health professions education. Medical Education, 52(6), 592-604. https://doi.org/10.1111/medu.13519

Caverzagie, K. J., Nousiainen, M. T., Ferguson, P. C., ten Cate, O., Ross, S., Harris, K. A., Busari, J., Bould, M. D., Bouchard, J., Iobst, W. F., Carraccio, C., Frank, J.R., \& ICBME Collaborators. (2017). Overarching challenges to the implementation of competency-based medical education. Medical Teacher, 39(6), 588-593. https://doi.org/10.1080/0142159X.2017.1315075

Durning, S. J., Lubarsky, S., Torre, D., Dory, V., \& Holmboe, E. (2015). Considering "nonlinearity" across the continuum in medical education assessment: Supporting theory, practice, and future research directions. Journal of Continuing Education in the Health Professions, 35(3), 232-243. https://doi.org/10.1002/chp.21298

Eva, K. W., Bordage, G., Campbell, C., Galbraith, R., Ginsburg, S., Holmboe, E., \& Regehr, G. (2016). Towards a program of assessment for health professionals: from training into practice. Advances in Health Sciences Education, 21(4), 897-913. https://doi.org/10.1007/s10459-015-9653-6 
Fraser, S. W., \& Greenhalgh, T. (2001). Coping with complexity: educating for capability. British Medical Journal, 323(7316), 799-803. https://doi.org/10.1136/bmj.323.7316.799

Gardner, A., Hase, S., Gardner, G., Dunn, S. V., \& Carryer, J. (2008). From competence to capability: a study of nurse practitioners in clinical practice. Journal of Clinical Nursing, 17(2), 250-258. https://doi.org/10.1136/bmjqs.2010.046714

General Medical Council. (2015). Developing a model for generic professional capabilities: A public consultation. London.

https://www.ombudsman.org.uk/sites/default/files/Developing_a_framework_for_generic_profe ssional capabilities form English_writeable final distributed.pdf 61568131.pdf

General Medical Council. (2017). Developing a model for generic professional capabilities. https://www.gmc-uk.org/-/media/documents/generic-professional-capabilities-model--0817_pdf70417127.pdf.

Ginsburg, S., McIlroy, J., Oulanova, O., Eva, K., \& Regehr, G. (2010). Toward authentic clinical evaluation: pitfalls in the pursuit of competency. Academic Medicine, 85(5), 780-786. https://doi.org/10.1097/ACM.0b013e3181d73fb6

Glass, J. (2014). Competency-based training is a model for incompetence. British Medical Journal, 348, g2909. https://doi.org/10.1136/bmj.g2909

Govaerts, M., \& Van der Vleuten, C. P. (2013). Validity in work-based assessment: expanding our horizons. Medical Education, 47(12), 1164-1174. https://doi.org/10.1111/medu.12289

Hanks, S., Coelho, C., \& Coster, R. (2018). Prepared for practice and equipped for employment: what do dental foundation trainers think of their trainees? British Dental Journal, 225(6), 549-555. https://doi.org/10.1038/sj.bdj.2018.756

Hawkins, R. E., Welcher, C. M., Holmboe, E. S., Kirk, L. M., Norcini, J. J., Simons, K. B., \& Skochelak, S. E. (2015). Implementation of competency-based medical education: are we addressing the concerns and challenges? Medical Education, 49(11), 1086-1102. https://doi.org/10.1111/medu.12831

Hay, D., Kinchin, I., \& Lygo-Baker, S. (2008). Making learning visible: the role of concept mapping in higher education. Studies in Higher Education, 33(3), 295-311. https://doi.org/10.1080/03075070802049251

Iedema, R. (2011). Creating safety by strengthening clinicians' capacity for reflexivity. BMJ Quality \& Safety, 20(Suppl 1), i83-i86. https://doi.org/10.1136/bmjqs.2010.046714

Jabareen, Y. (2009). Building a conceptual framework: philosophy, definitions, and procedure. International Journal of Qualitative Methods, 8(4), 49-62. https://doi.org/10.1177/160940690900800406

Kalet, A., Chou, C. L., \& Ellaway, R. H. (2017). To fail is human: remediating remediation in medical education. Perspectives on Medical Education, 6(6), 418-424. https://doi.org/10.1007/s40037017-0385-6

Mann, K., Gordon, J., \& MacLeod, A. (2009). Reflection and reflective practice in health professions education: a systematic review. Advances in Health Sciences Education, 14(4), 595-621. https://doi.org/10.1007/s10459-007-9090-2

Meyer, J. H., \& Land, R. (2005). Threshold concepts and troublesome knowledge (2): Epistemological considerations and a conceptual framework for teaching and learning. Higher Education: The International Journal of Higher Education and Educational Planning, 49(3):373-388. https://doi.org/10.1007/s10734-004-6779-5

Miller, G. E. (1990). The assessment of clinical skills/competence/performance. Academic Medicine, 65(9), S63-7. https://doi.org/10.1097/00001888-199009000-00045

Monrouxe, L., Bullock, A., Cole, J., Gormley, G., Kaufhold, K., Kelly, N., Mattick, K., Rees, C., \& Scheffler, G. (2014). How prepared are UK medical graduates for practice? Final report from a programme of research commissioned by the General Medical Council, UK. GMC.

Monrouxe, L. V., \& Rees, C. E. (2017). Healthcare professionalism: improving practice through reflections on workplace dilemmas. John Wiley \& Sons. https://doi.org/10.1002/9781119044475

Neve, H., Gilbert, K., \& Lloyd, H. (2018). PBL as learning vehicle, threshold concept or capability?: audio-diary research in medical education. In M. Savin-Baden, \& G. Tombs. Threshold concepts in problem-based learning (pp. 49-64). Brill Sense.

https://doi.org/10.1163/9789004375123_005 
Neve, H., \& Hanks, S. (2016). When I say........ capability. Medical Education, 50(6), 610-611. https://doi.org/10.1111/medu.12956

O'Connell, J., Gardner, G., \& Coyer, F. (2014). Beyond competencies: using a capability framework in developing practice standards for advanced practice nursing. Journal of Advanced Nursing, 70(12), 2728-2735. https://doi.org/10.1111/jan.12475

Perkins, D. (2006). Constructivism and troublesome knowledge. In: J. Meyer J \& R. Land, R (Eds.), Overcoming barriers to student understanding: Threshold concepts and troublesome knowledge (pp. 33-47). Routledge.

Pusic, M. V., Santen, S. A., Dekhtyar, M., Poncelet, A. N., Roberts, N. K., Wilson-Delfosse, A. L., \& Cutrer, W. B. (2018). Learning to balance efficiency and innovation for optimal adaptive expertise. Medical Teacher, 40(8), 820-827. https://doi.org/10.1080/0142159X.2018.1485887

Rees, C., \& Richards, L. (2004). Outcomes-based education versus coping with complexity: should we be educating for capability? Medical Education, 38(11), 1203-1203. https://doi.org/10.1111/j.13652929.2004.02039.x

Rethans, J-J., Norcini, J. J., Barón-Maldonado, M., Blackmore, D., Jolly, B. C., LaDuca, T., Lew, S., Page, G. G., \& Southgate, L. H. (2002). The relationship between competence and performance: implications for assessing practice performance. Medical Education, 36(10), 901-909. https://doi.org/10.1046/j.1365-2923.2002.01316.x

Saldaña, J. (2013). The coding manual for qualitative researchers. SAGE.

Sandars, J., \& Sarojini Hart, C. (2015). The capability approach for medical education: AMEE Guide No. 97. Medical Teacher, 37(6), 510-520. https://doi.org/10.3109/0142159X.2015.1013927

Schuwirth, L., \& Van der Vleuten, C. (2011). Programmatic assessment: From assessment of learning to assessment for learning. Medical Teacher, 33(6): 478-485. https://doi.org/10.3109/0142159X.2011.565828

Stephenson, J. (1998). The concept of capability and its importance in higher education. In J. Stephenson, \& M. Yorke (Eds.), Capability and quality in higher education (pp. 1-13): Kogan Page.

Swaffield, S. (2011). Getting to the heart of authentic assessment for learning. Assessment in Education: Principles, Policy \& Practice, 18(4), 433-449. https://doi.org/10.1080/0969594X.2011.582838

ten Cate, O., Graafmans, L., Posthumus, I., Welink, L., \& van Dijk, M. (2018). The EPA-based Utrecht undergraduate clinical curriculum: Development and implementation. Medical Teacher, 40(5), 506-513. https://doi.org/10.1080/0142159X.2018.1435856

ten Cate, O., \& Scheele, F. (2007). Competency-based postgraduate training: can we bridge the gap between theory and clinical practice? Academic Medicine, 82(6), 542-547. https://doi.org/10.1097/ACM.0b013e31805559c7

Teunissen, P. W., Watling, C., Schrewe, B., Asgarova, S., Ellaway, R., Myers, K., Topps, M., Bates, J. (2021). Contextual Competence: how residents develop competent performance in new settings. Medical Education, Early View Feb 25. https://doi.org/10.1111/medu.14517

Wass, V., Van der Vleuten, C., Shatzer, J., \& Jones, R. (2001). Assessment of clinical competence. The Lancet, 357(9260), 945-949. https://doi.org/10.1016/S0140-6736(00)04221-5

Wheelahan, L. (2007). What kind of curriculum, pedagogy \& qualifications do we need for an uncertain future? In M. Osborne, M. Houston, N. Toman (Eds.), The pedagogy of lifelong learning: understanding effective teaching and learning in diverse contexts (pp 143-153). Routledge.

Whitehead, B., \& Holmes, D. (2011). Are newly qualified nurses prepared for practice? Nursing Times, 107(19-20), 20-23. 